\title{
Urothelial carcinoma of the upper urinary tract diagnosed via FGFR3 mutation detection in urine: a case report
}

Daniel M Silverberg

\begin{abstract}
Background: Upper urinary tract cancer is typically diagnosed with urine cytology and imaging techniques. These assays can be limited by sensitivity, specificity, or technical issues making some diagnoses difficult.

Case presentation: A 73-year old man presented to the clinic with a right renal pelvis filling defect that was detected by a CT-scan performed for unrelated reasons. Urine cytology was negative. Cystoscopy, retrograde pyelogram, and partial ureteroscopy were unable to visualize the lesion resulting in an indeterminate diagnosis. A subsequent $C T$ scan confirmed the renal lesion which appeared to have become larger and was consistent with urothelial carcinoma. A urine based genetic assay was used to test for the presence of urothelial carcinoma. This assay evaluates the presence of mutations in fibroblast growth factor receptor 3 (FGFR3). Mutations in FGFR3 are known to be associated with urothelial carcinoma and have a positive predictive value of $95 \%$ when detected in patients with no history of TCC. A mutation in exon 10 (Y375C) of FGFR3 was identified. Nephroureterectomy was performed and the subsequent pathology confirmed urothelial carcinoma. In addition, PCR analysis on isolated tumor tissue indicated the tumor carried the same FGFR3 mutation as that of the DNA isolated from urine, consistent with the tumor being the origin of the mutant DNA.
\end{abstract}

Conclusion: This study indicates that the FGFR3 urine assay, which was originally developed to monitor bladder cancer, is also a useful tool for diagnosing upper urinary tract cancer in a real-life setting.

Keywords: Cancer, Ureter, Renal pelvis, FGFR3, PCR, Kidney, Bladder, Urothelial carcinoma, Diagnosis, CertNDx

\section{Background}

Urothelial carcinoma is the fourth most common cancer and can be located in the lower or upper urinary tract. Upper urinary tract carcinomas, which are nearly all urothelial carcinomas, are uncommon and account for only $5-10 \%$ of all urinary carcinomas $[1,2]$.

Diagnosis of upper urinary tract cancer has traditionally depended on urine cytology and imaging techniques including CT urography, retrograde pyelography and direct pyeloscopy [2,3]. These assays are all useful but individually can be limited by sensitivity, specificity, or technical issues. In fact, the American Urologic Association and European Association of Urology recommend the use of multiple approaches for diagnosing possible upper urinary tract malignancies $[2,4]$.

Correspondence: DanSilverberg1@gmail.com

5018 Medical Center Circle, Suite 240, Allentown, PA 18106, USA
Activating mutations in the fibroblast growth factor receptor 3 (FGFR3) occur in $>50 \%$ of low-grade and lowstage bladder tumors (about 64-85\% of pTa tumors carry FGFR3 mutations) [5-9]. Eight common FGFR3 mutations in 3 exons (exons 7, 10, and 15) are associated with $>90 \%$ of all known mutant FGFR3 positive bladder cancers. Several urine-based genetic assays have been developed to detect FGFR3 mutations in patients with bladder cancer with sensitivity ranging from $58-92 \%[8,10-12]$.

Here we describe a case in which a urine-based FGFR3 genetic test, (CertNDx ${ }^{\mathrm{Tm}}$ Bladder Cancer Assay [Predictive Biosciences, Lexington, MA, USA]) was pivotal in diagnosing an upper urinary tract carcinoma that was difficult to diagnose by cytology or endoscopy.

\section{Case presentation}

A 73-year-old male presented to Urology Specialists of the Lehigh Valley in October 2010 with a right renal

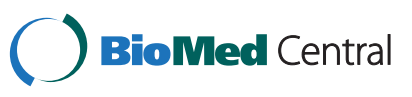

(c) 2012 Silverberg; licensee BioMed Central Ltd. This is an Open Access article distributed under the terms of the Creative Commons Attribution License (http://creativecommons.org/licenses/by/2.0), which permits unrestricted use, distribution, and reproduction in any medium, provided the original work is properly cited. 

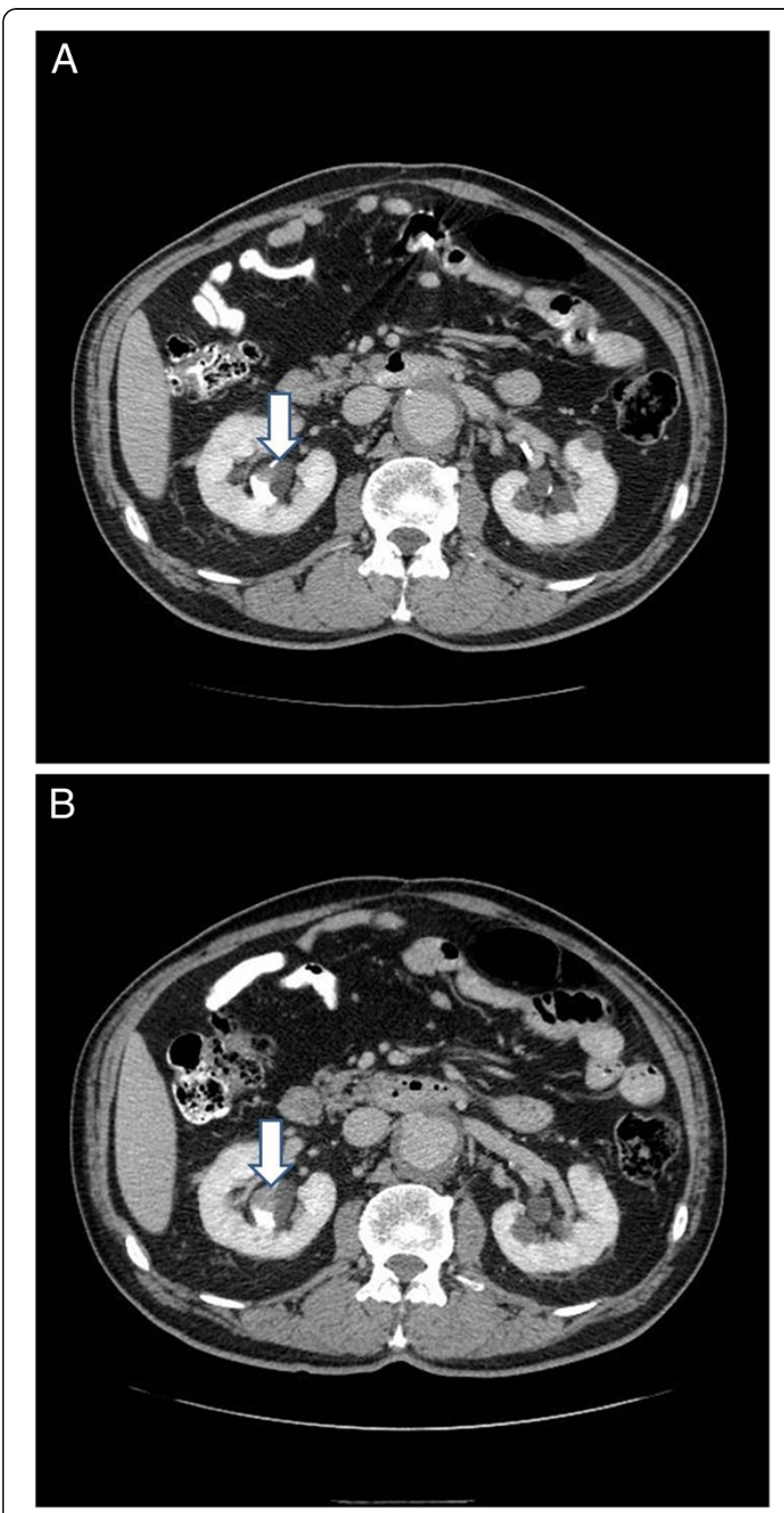

Figure $1 \mathrm{CT}$ scans indicating the presence of the tumor (arrow) from (A) September 2010 and (B) June 2011.

pelvis filling defect, potentially a urothelial carcinoma. The lesion was detected by CT scan (Figure 1A) performed for unrelated reasons and had not been visible on prior CT scans.

The patient had smoked for 20 years but had stopped smoking approximately 10 years prior. He previously had non-small cell lung cancer that was treated with radiation and chemotherapy in 2001-2002 and was in remission. In 2001-2002 he had a coronary artery bypass graft and an abdominal aortic aneurysm repaired. The patient was asymptomatic from these conditions at the time of presentation.

A physical examination was normal. The laboratory values were within normal limits. The patient had no urinary complaints. Urine cytology and cystoscopy were negative. Right retrograde pyelogram disclosed a complete ureteral duplication. Complete ureteropyeloscopy was not possible due to the narrow ureters. Retrograde pyelogram of the lower pole was performed and was normal. It was not possible to perform a retrograde pyelogram of the upper pole unit because the ureter was only about $1 \mathrm{~mm}$ in diameter, where a normal ureter is $3-4 \mathrm{~mm}$ in diameter. The instruments used in our practice are sized and scaled for a normal ureter and not for this small ancillary ureter. An attempted pyelogram was unsuccessful as the contrast did not fill the ureter or renal pelvis.

Approximately 6-months following initial urological evaluation, CT scan confirmed the presence of the mass which now appeared larger (Figure 1B). These findings were consistent with urothelial carcinoma of the renal pelvis, although urine cytology was again negative.

Prior to initiating more invasive diagnostic methods, a real-time PCR-based genetic assay was used to determine if the patient's urine contained DNA that carried FGFR3 mutations in exons 7, 10, or 15 [13]. This assay has $99.9 \%$ specificity for urothelial carcinoma. A mutation was detected in exon 10 (Y375C) of FGFR3, indicating a high probability $(94.7 \% \mathrm{PPV})$ that the patient had urothelial carcinoma.

The patient underwent right nephroureterectomy. The arterial anatomy precluded an upper pole nephroureterectomy. The tumor involved the renal pelvis of the upper pole collecting system. Upon cut sections, the kidney exhibited an ill-defined partially raised, partially nodular tan-pink dense focus, located in the renal pelvis of the upper pole, which measured $1.5 \mathrm{~cm}$ greatest dimension. This focal area appeared limited to the upper pole renal pelvis/calyx and abutted but did not involve kidney parenchyma or peripelvic fat. Due to autolysis, tumor grade was somewhat difficult to provide definitively. However, the pathologist favored a designation of low grade urothelial carcinoma (WHO 2004). No lamina propria, renal parenchyma or peri-nephric fat involvement was identified such that the tumor stage was Ta,NO,M0. Tumor tissue obtained from the archival paraffin block was found, using quantitative PCR, to have an exon 10 (Y375C) mutation, which is consistent with the tumor being the source of the mutant DNA found in the urine.

Since the nephroureterectomy, the patient has been monitored for recurrent cancer. We performed a postoperative CertNDx test in March 2012, 7 months after the nephroureterectomy, which was negative for the presence of FGFR3 mutant DNA. In addition following the uncomplicated postoperative course, the patient had surveillance cystoscopies in November 2011 and February 2012, both of which were negative. As part of the continuing follow-up, the patient will undergo surveillance cystoscopy several times per year for the 
foreseeable future. In view of the negative CertNDx test, upper tract imaging has not yet been performed. The left kidney has not been examined as it was normal at the time of the most recent CT scan (June 2011).

\section{Discussion}

We describe a case in which the urine based CertNDx ${ }^{\text {tm }}$ Bladder Cancer Assay, for mutations in FGFR3, played a pivotal role in diagnosing urothelial cancer in the urinary tract of a patient. The case was particularly difficult. A filling defect in the right renal pelvis was detected by CT scan raising the possibility that the patient had urothelial carcinoma. However, CT scans are nonspecific and filling defects are also visible in a number of other pathologies [14]. Therefore, it was important to characterize this lesion further before performing nephroureterectomy.

Diagnosis of upper urinary tract urothelial carcinoma depends heavily upon imaging and cytology. However, in this case a number of standard imaging techniques were unable to diagnose the lesion with certainty, and the urine cytology was negative. The patient had a complete ureteral duplication and the ureteral orifice to the narrow upper pole ureter was right at the bladder neck. Direct endoscopy of the upper pole moiety was attempted but proved to be impossible due to these anatomic issues. The urine cytology may have been negative due to its inherent poor sensitivity (from $4-31 \%$ ) for detecting low-grade tumors $[15,16]$.

Analysis of mutations in the FGFR3 gene, using the urine based CertNDx ${ }^{\mathrm{Tm}}$ Bladder Cancer Assay, detected cancer indicating that the tumor was malignant; which was subsequently confirmed by pathology. This assay was originally developed for monitoring patients with a history of bladder cancer. In a Phase III, multicenter, prospective study of 748 patients with hematuria and no history of bladder cancer, this assay demonstrated a specificity of $99.9 \%$ and a positive predictive value of $95.2 \%$ [13]. In a prior clinical trial of 200 patients with lowgrade non-muscle-invasive bladder tumors, analysis of FGFR3 mutations identified 3 patients with upper urinary tract recurrent cancer that were not detected by cystoscopy [10]. This study is the first to show that this assay, in a community based setting, can identify upper urinary tract urothelial carcinoma.

A number of urine based biomarkers for bladder cancer are being developed that are either protein or genetically based. The different protein assays are predicated on the observation that urine levels of certain proteins are altered when cancer is present. These assays monitor proteins that include bladder tumor antigens, nuclear matrix protein 2, bladder tumor cell-associated mucin, carcinoembryonic antigen, BLCA-1 and BLCA-4 transcription factors, matrix metalloproteinase-9, carcinoembryonic antigen-related cell adhesion molecule, survivin, or telomerase [15,17]. The genetic assays, besides FGFR3 mutational analysis, detect chromosomal abnormalities (such as aneuploidy, etc.) using FISH (fluorescent in-situ hybridization), changes in gene methylation, and microRNA expression [15]. Currently, only a small number of these biomarkers are commercially available in the US, and how the others will translate into the clinic is difficult at this time to predict [15]. Presently, the FGFR3 assay is the only urine based genetic assay that is commercially available.

\section{Conclusion}

This case study demonstrates that the FGFR3 assay is a beneficial addition to the methodologies used in real-life clinical settings for diagnosing not only bladder cancer but also for diagnosing the less common and more difficult to detect upper urinary tract urothelial carcinoma.

\section{Consent}

The patient has given written consent for this case report to be published.

\section{Competing interests}

The author received a nominal fee for his expertise and work on this case report.

\section{Authors' contributions}

DS cared for the patient, was instrumental in the development of the manuscript, and approved the final version.

\section{Authors' information}

Urology Specialists of Lehigh Valley, 5018 Medical Center Circle, Suite 240. Allentown, PA 18106, USA.

\section{Acknowledgements}

I would like to thank Chris Walls from Predictive Biosciences Inc. for valuable discussion regarding the results and manuscript, and Elizabeth Goodwin PhD for editorial assistance which was supported by Predictive Biosciences Inc.

Received: 21 December 2011 Accepted: 11 July 2012

Published: 8 August 2012

\section{References}

1. Chow WH, Dong LM, Devesa SS: Epidemiology and risk factors for kidney cancer. Nat Rev Urol 2010, 7:245-257.

2. Rouprêt M, Zigeuner R, Palou J, Boehle A, Kaasinen E, Sylvester R, Babjuk M, Oosterlinck W: European guidelines for the diagnosis and management of upper urinary tract urothelial cell carcinomas: 2011 update. Eur Urol 2011, 59:584-594.

3. Vikram R, Sandler CM, Ng CS: Imaging and staging of transitional cell carcinoma: part 2, upper urinary tract. AJR Am J Roentgenol 2009, 192:1488-1493.

4. Brausi M, Witjes JA, Lamm D, Persad R, Palou J, Colombel M, Buckley R, Soloway M, Akaza $H$, Böhle $A$ : A review of current guidelines and best practice recommendations for the management of nonmuscle invasive bladder cancer by the international bladder cancer group. J Urol 2011, 186:2158-2167.

5. Cappellen D, De Oliveira C, Ricol D, de Medina S, Bourdin J, Sastre-Garau X, Chopin D, Thiery JP, Radvanyi F: Frequent activating mutations of FGFR3 in human bladder and cervix carcinomas. Nat Genet 1999, 23:18-20.

6. van Rhijn BW, Vis AN, van der Kwast TH, Kirkels WJ, Radvanyi F, Ooms EC, Chopin DK, Boevé ER, Jöbsis AC, Zwarthoff EC: Molecular grading of urothelial cell carcinoma with fibroblast growth factor receptor 3 and MIB-1 is superior to pathologic grade for the prediction of clinical outcome. J Clin Oncol 2003, 21:1912-1921. 
7. van Rhijn BW, Lurkin I, Chopin DK, Kirkels WJ, Thiery JP, van der Kwast TH, Radvanyi F, Zwarthoff EC: Combined microsatellite and FGFR3 mutation analysis enables a highly sensitive detection of urothelial cell carcinoma in voided urine. Clin Cancer Res 2003, 9:257-263.

8. van Rhijn BW, Zuiverloon TC, Vis AN, Radvanyi F, van Leenders GJ, Ooms BC, Kirkels WJ, Lockwood GA, Boevé ER, Jöbsis AC, Zwarthoff EC, van der Kwast TH: Molecular grade (FGFR3/MIB-1) and EORTC risk scores are predictive in primary non-muscle-invasive bladder cancer. Eur Urol 2010, 58:433-441.

9. Billerey C, Chopin D, Aubriot-Lorton MH, Ricol D, Gil Diez de Medina S, Van Rhijn B, Bralet MP, Lefrere-Belda MA, Lahaye JB, Abbou CC, Bonaventure J, Zafrani ES, van der Kwast T, Thiery JP, Radvanyi F: Frequent FGFR3 mutations in papillary non-invasive bladder ( $\mathrm{PTa}$ ) tumors. Am J Pathol 2001, 158:1955-1959.

10. Zuiverloon TC, van der Aa MN, van der Kwast TH, Steyerberg EW, Lingsma HF, Bangma CH, Zwarthoff EC: Fibroblast growth factor receptor 3 mutation analysis on voided urine for surveillance of patients with low-grade nonmuscle-invasive bladder cancer. Clin Cancer Res 2010, 16:3011-3018.

11. van Oers JM, Lurkin I, van Exsel AJ, Nijsen Y, van Rhijn BW, van der Aa MN, Zwarthoff EC: A simple and fast method for the simultaneous detection of nine fibroblast growth factor receptor 3 mutations in bladder cancer and voided urine. Clin Cancer Res 2005, 11:7743-7748.

12. Miyake M, Sugano K, Kawashima K, Ichikawa H, Hirabayashi K, Kodama T, Fujimoto H, Kakizoe T, Kanai Y, Fujimoto K, Hirao Y: Sensitive detection of FGFR3 mutations in bladder cancer and urine sediments by peptide nucleic acid-mediated real-time PCR clamping. Biochem Biophys Res Commun 2007, 362:865-871.

13. Karnes RJ, Fernandez CA, Shuber AP: A non-invasive multi-analyte urine based diagnostic assay for urothelial cancer of the bladder in the evaluation of hematuria. Mayo Clinic Proc 2012, (in press).

14. Khan AN: Transitional cell carcinoma imaging. 2000. http://emedicine medscape.com/article/381323-overview (accessed 09/13/11).

15. Tilki D, Burger M, Dalbagni G, Grossman HB, Hakenberg OW, Palou J, Reich O, Rouprêt M, Shariat SF, Zlotta AR: Urine markers for detection and surveillance of non-muscle-invasive bladder cancer. Eur Urol 2011, 60:484-492.

16. Lotan Y, Roehrborn CG: Sensitivity and specificity of commonly available bladder tumor markers versus cytology: results of a comprehensive literature review and meta-analyses. Urology 2003, 61(1):109-118.

17. Fernández CA, Wszolek MF, Loughlin KR, Libertino JA, Summerhayes IC, Shuber AP: A novel approach to using matrix metalloproteinases for bladder cancer. J Urol 2009, 182:2188-2194.

doi:10.1186/1471-2490-12-20

Cite this article as: Silverberg: Urothelial carcinoma of the upper urinary tract diagnosed via FGFR3 mutation detection in urine: a case report. BMC Urology 2012 12:20.

\section{Submit your next manuscript to BioMed Central and take full advantage of:}

- Convenient online submission

- Thorough peer review

- No space constraints or color figure charges

- Immediate publication on acceptance

- Inclusion in PubMed, CAS, Scopus and Google Scholar

- Research which is freely available for redistribution 